Copyright Infopro Digital Limited 2020. All rights reserved. You may share using our article tools. This article may be printed for the sole use of the Authorised User (named subscriber), as outlined in our terms and conditions. https:/www.infopro-insight.com/termsconditions/insight-subscriptions

Research Paper

\title{
The liquefied natural gas spot market and valuation of the rerouting option
}

\section{Hélyette Geman ${ }^{1,2}$ and Sofia Philippou ${ }^{1}$}

\author{
${ }^{1}$ Department of Economics, Mathematics and Statistics, Birkbeck, University of London, \\ Malet Street, Bloomsbury, London WC1E 7HX, UK; \\ emails: hgeman@hotmail.com, sphili05@mail.bbk.ac.uk \\ ${ }^{2}$ Department of Applied Mathematics and Statistics, Johns Hopkins University, \\ 3400 North Charles Street, Baltimore, MD 21218, USA
}

(Received March 10, 2020; revised April 30, 2020; accepted October 2, 2020)

\section{ABSTRACT}

The liquefied natural gas (LNG) market has experienced remarkable changes in the last few years, with long-term contracts being replaced by short-term ones and optionalities being granted by suppliers in the context of a large increase in natural gas production. Flexible LNG contracts give buyers the option to redirect their cargo if they identify a higher spot price at a point different from the original destination. The goal of this paper is twofold: (1) to describe the new outlook of LNG markets, which has become more and more spot-centric, with Asian LNG futures bringing transparency to spot and forward prices; and (2) to address the valuation of the rerouting option, a number that must be accounted for by the buyer when assessing the profitability of a given cargo. As an example, we apply the rerouting option valuation methodology to a scenario in which the supplier is the United States, the original destination is Germany and the alternative destination is Japan. We assume the rerouting of the vessel takes place when the cargo reaches the waters of Germany. This approach can be used for any group of three countries by adjusting the 
transportation costs. Our paper also depicts the value of the option as a function of the volatility of the natural gas spot prices in the alternative destination.

Keywords: natural gas markets; spot liquefied natural gas (LNG) prices; liquefied natural gas (LNG) tankers; rerouting option; transportation costs.

\section{INTRODUCTION}

World natural gas markets experienced remarkable changes between 2009 and 2019 . On the demand side, natural gas is being perceived more and more as a replacement for oil and coal in the mid to long term because it produces fewer emissions. Natural gas also plays a key role in the energy mix for power generation, in particular because flexible combined cycle gas turbines (CCGTs) are necessary to complement renewable sources of electricity, such as solar and wind, as a result of their intermittent nature. On the supply side, two elements have deeply transformed the natural gas market: the increase of natural gas production, specifically as a consequence of the large production of shale gas coming from the United States, and the expansion of unprecedented scale of the liquefied natural gas (LNG) industry as of 2009 (see, for instance, Corbeau and Ledesma 2016; Flower 2016), with a large number of small LNG tankers being built and allowing gas suppliers to rapidly serve regions where spot prices are momentarily high. The growth of the fleet was motivated by recent US exports and the Fukushima nuclear reactor disaster in 2011, which forced Japan, a major economy, to rapidly turn to the production of electricity using natural gas.

In parallel, the emergence of an LNG market has taken place in Asia around Japan, Taiwan and South Korea, while Singapore has become the center of LNG derivatives trading. This region crucially depends on LNG imports, as it produces very little natural gas of its own. As a result, there has been a remarkable increase in LNG trading worldwide in recent years. Accordingly, global LNG trading set a record in 2018, reaching 316.5 million tonnes and marking an increase of $9.8 \%$ year on year from 2017 (International Gas Union 2018).

Traditionally, LNG has been traded on long-term oil-indexed LNG contracts, necessary for providing supply security to buyers and financial security to producers. Recently, however, these contracts have been in decline, owing to small LNG tankers that are ready to supply LNG at any given point with short notice, creating a real market for LNG and, hence, a "deindexation" to oil. These contracts also became much less desirable when crude oil prices collapsed from US\$120 per barrel in January 2014 to less than US\$40 in January 2016. The same phenomenon of "deindexation" to oil prices had happened in European natural gas markets by 2009.

In the old contracts, importers typically agreed to the rules of the suppliers; options were rarely present, in particular the ability to divert cargo from its original 
destination (Carriere 2018). The new contracts are signed by buyers interested in the volatility of spot prices and all contract features that allow one to benefit from this. Accordingly, we will exhibit both the price and the change in price of the rerouting option in the case of a higher volatility of LNG prices.

The rest of this paper is organized as follows. Section 2 describes the current structure of the LNG market and presents the relevant literature. Section 3 presents the methodology for rerouting option pricing. Section 4 discusses the data used in the analysis, particularly the model that describes the spot price dynamics as well as the various transportation costs. Section 5 displays the option valuation and its vega/ sensitivity to volatility. Section 6 concludes.

\section{GLOBAL LIQUEFIED NATURAL GAS MARKET OVERVIEW}

Jensen (2004) investigates the development of a global LNG market and correctly forecasts that flexible, short-term contracts will continue to rapidly increase in number and total volume. Hartley (2015) develops a model of the costs and benefits of an optimal long-term LNG contract, which is defined as one that gives the largest combined expected net present value to the trading parties. Increased spot market liquidity is analyzed in terms of how it affects such optimal contracts. The study concludes that the amount of LNG traded in long-term contracts is likely to further decline and that contracts will offer much greater volume and destination flexibility in future. Shi et al (2016) examine the impact of a change in East Asia's pricing benchmark on regional and global gas markets. They find that both price benchmark changes and contract flexibility improvements will create an overall benefit worldwide, and for East Asia importers in particular. Carriere (2018) observes that Japan is moving away from crude-oil-based pricing toward a more diverse LNG price structure, while Japanese buyers no longer accept uncompetitive destination restrictions in their supply contracts.

In relation to our paper, Rodriguez (2008) introduces a real option model for the valuation of destination flexibility in long-term LNG supplies, which he evaluates "on average" over a twenty-year period. Besides choosing a different model for the spot price dynamics, our paper recognizes the specific durations of a tanker's voyage to reach two different points in the world as well as a clear maturity for the option attached to a given cargo.

In recent years, the number of traded flexible contracts has grown progressively. Accordingly, in 2018, short-term LNG trade reached 99 million tonnes, an increase of 14.5 million tonnes year on year, and accounted for $31 \%$ of the total gross LNG trade. This substantial expansion can be attributed to an increasingly flexible LNG supply from Russia and North America (International Gas Union 2018). As a result of this significant increase in short-term LNG trading, in 2018, S\&P Global Platts 
launched the Platts Gulf Coast Marker (GCM) index, reflecting the daily export value of LNG traded free on board (FOB) from the US Gulf Coast. ${ }^{1}$

In addition, Cheniere Energy, the second largest supplier of LNG worldwide, sells $20 \%$ of its production in flexible contracts. For example, in March 2018, a US LNG cargo ship departed from Cove Point and headed to Asia but was resold and diverted to the United Kingdom to meet that country's gas demand after Europe was hit by extreme cold weather (Mills 2018). Ledesma and Fulwood (2019) analyze the current short-term LNG trading setting, particularly the "Cheniere model", and discuss which LNG models could underpin the next wave of LNG liquefaction capacity. They also investigate whether market participants (aggregators, portfolio companies and intermediaries) have the financial and commercial capacity to support such new models, and they announce that a fully functioning spot-traded LNG market is rapidly developing.

It is clear that the arrival of new, very large players, both exporters and importers (such as the United States and China), has increased the trading activity in Platt's Japan Korean Marker (JKM) in the last few years; in turn, the liquidity and transparency of Platt's JKM has created a rise in spot LNG trading.

\subsection{Major LNG exporting countries}

For the last decade, Qatar has been the world's largest LNG exporter, accounting for $24.9 \%$ of global LNG. However, if volumes remain stable, Qatar's market share is forecasted to decrease as other countries, particularly Australia and the United States, continually invest in increasing their LNG production through new projects and infrastructure that will become fully operational over the coming years (International Gas Union 2018).

Australia, the second largest exporter of LNG, retains a market share of $21.7 \%$ of global LNG exports and delivers most of its LNG to Japan and China. Australia has seven operating LNG terminals. The North West Shelf Venture, an investment in excess of AU $\$ 33.5$ billion, has been operating since 1989 and produces 16.3 million tonnes per annum of LNG. Darwin LNG started production in 2006 and has a capacity of around 3.7 million tonnes per annum. Pluto was commissioned in 2012 and has one production train with a capacity of 4.7 million tonnes per annum. Queensland Qurtis LNG, operated by Shell, began producing LNG in 2014 and has two trains with a combined capacity of 8.5 million tonnes per annum. Gladstone LNG and Australia Pacific LNG have been online since 2015. The Gorgon project, based on Barrow Island, is one of the world's largest natural gas projects, with a production capacity of around 2.6 million cubic feet of natural gas and 15.6 million metric

\footnotetext{
${ }^{1}$ See "Platts GCM ${ }^{\mathrm{TM}}$ (Gulf Coast Marker) LNG price assessment". URL: https://bit.ly/3lysW01.
} 
tonnes of LNG. The first LNG cargo left Gorgon in March 2016. Wheatstone has been operating since 2017 and has a combined capacity of 8.9 million metric tonnes per annum from two trains. ${ }^{2}$

In 2018, Malaysia was the third largest supplier, with a market share of $7.7 \%$. From January through to June 2019, US net natural gas exports averaged 4.1 billion cubic feet per day, more than double the average net exports of 2 billion cubic feet for the whole of 2018 (according to a US Energy Information Administration (EIA) report of October 2019). Two LNG exporting terminals have been operating in the United States since 2016: the Sabine Pass in Louisiana and Cove Point in Maryland. Four more projects went online in 2019: Corpus Christi LNG in Texas; Cameron LNG in Louisiana; Elba Island LNG in Georgia; and Freeport LNG in Texas (US Energy Information Administration 2019). Nigeria was in fifth place in 2018, with a market share of $6.5 \%$; it is likely to be surpassed by Russia as production from Yamal LNG increases (International Gas Union 2018).

\subsection{Major LNG-importing countries}

The Asia-Pacific basin is the largest importing region of global LNG. In 2018, Japan remained the largest importing country worldwide, with a market share of $25.4 \%$ of global LNG to fuel its vibrant economy; this was in the absence of significant renewables that would have allowed the full replacement of the Fukushima nuclear plant. China, the second largest importing country, had a market share of $16.7 \%$ by the end of 2018; this was the result of an environmental policy change from coal to gas, as some major cities had passed the threshold of acceptable pollution levels. Other large consuming countries are South Korea, India, Spain and Turkey (International Gas Union 2018).

European LNG imports expanded for the fourth consecutive year in 2018, reaching a growth level of $7.3 \%$ year on year. Increased LNG imports in Europe are due to a number of reasons, such as the decline of domestic production of natural gas (Netherlands, United Kingdom), the increase of electricity production in gas-fired plants, lower French nuclear generation and weak hydrogen generation. Germany, a major economy, has totally moved away from nuclear electricity and wishes to respect the Paris Accord in terms of coal emissions. Africa and the Middle East remain the leaders in European LNG supply, although imports from the United States did grow at a higher proportion in 2018 and this trend is expected to continue (International Gas Union 2018).

\footnotetext{
${ }^{2}$ See "LNG exports" on the Australian Petroleum Production and Exploration Association website. URL: https://bit.ly/2Is5YJR.
} 


\section{THE REROUTING OPTION}

Optionalities are numerous in the world of energy, the context in which the important notion of "real options" was introduced (see Dixit and Pindick 1994). They also exist in the world of shipping, where "time charters contracts with purchase options" are often signed between ship owners and charterers. In this paper, we are interested in the rerouting option often included in short- to medium-term contracts. Rodriguez (2008) looked at long-term contracts, analyzing a "destination option" with no specific maturity and averaged over a period of twenty years.

Instead, we analyze a specific cargo's route and the option that gives the buyer the right to get the LNG delivered at a point $\mathrm{B}$ rather than the point A targeted at departure; the option is exercised at some intermediary point $\mathrm{C}$, also specified at date 0 , when the tanker departs and the contract is signed between the supplier/ charterer and the buyer of the LNG. Hence, the maturity of the option is the date $T_{1}$, at which point $\mathrm{C}$ will be reached. The additional transportation costs are paid by the party who is "long" in the option. The buyer of the option is typically a natural gas company or a hedge fund that will buy LNG from a supplier and then resell the LNG to the local market where the delivery takes place.

We consider the case of LNG coming from the United States, where the original destination is Germany (point $\mathrm{A}$ ). We suppose that point $\mathrm{C}$ is identical or very close to the following: point A, namely in Germany's territorial waters; the point at which the tanker either continues into the harbor in Germany or is diverted to Japan (point B); and the time when the option is exercised. The decision to exercise the option will be based on a comparison between the spot price in Germany at $T_{1}$ (the date of arrival of the tanker) and a forward price that can be locked in at that moment $\left(T_{1}\right)$ for delivery in Japan at date $T$. Note that the payoff of the option will not take place at the date when it is fully known, but at date $T$, when LNG is delivered in Japan against the payment of the forward price contracted at date $T_{1}$. This is why the value of the option at date 0 will be discounted from $T$ to 0 . Its payoff at date $T$ is equal to

$$
C(T)=\max \left(0, f_{\mathrm{J}}^{T}\left(T_{1}\right)-S_{\mathrm{G}}\left(T_{1}\right)-\mathrm{ATC}\right),
$$

where $C(T)$ is the option price at date $T, f_{\mathrm{J}}^{T}\left(T_{1}\right)$ is the forward price in Japan observed at date $T_{1}$ for LNG delivery at date $T, S_{\mathrm{G}}\left(T_{1}\right)$ is the spot price in Germany for LNG delivery at date $T_{1}$, ATC is the additional transportation cost when rerouting the vessel at date $T_{1}$ from Germany to deliver LNG to Japan at date $T, T$ is two months $\left(\frac{2}{12}\right)$, and $T_{1}$ is one month $\left(\frac{1}{12}\right)$.

\section{DATA DESCRIPTION AND SPOT PRICE DYNAMICS}

For our analysis, we use spot prices from the German Gaspool (GPL) index and the Japan Korean Marker (JKM, published by Platts) index, provided by the ICE 
FIGURE 1 GPL index spot price trajectory.

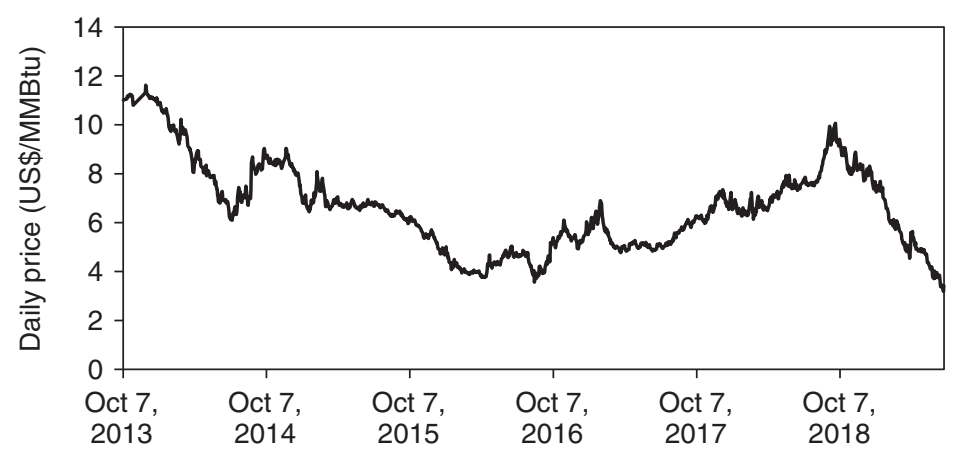

Daily prices presented in US\$/MMBtu for the GPL index for the period October 7, 2013-June 28, 2019. Source: Bloomberg.

Endex and the New York Mercantile Exchange, respectively, and accessed through Bloomberg.

We choose to use prices from the GPL index for LNG delivery in Germany because Germany is the largest gas-consuming country in Europe, with its first LNG terminal on the way in Brunsbuttel. Once the terminal is fully functional, Germany will gain access to the global LNG market and is poised to become one of the major European LNG importers. In addition, we choose the Platts JKM index to represent the LNG price in Japan, since the JKM index is the LNG benchmark price assessment that reflects the spot market value of cargo delivered to Japan, South Korea, China and Taiwan. ${ }^{3}$

For the spot price, we use the first nearby futures contract, namely the one-monthahead futures contract. JKM trades in US\$/MMBtu, while GPL trades in /MWh; thus, GPL prices have been converted to US\$/MMBtu at each date of analysis. Spot prices for each index are plotted in Figures 1 and 2.

\subsection{Spot price model}

We consider the price trajectories displayed above by the GPL and JKM indexes to suggest a mean-reverting process, a choice that is supported by the economics of the market. In order to ensure positivity of prices, we define $X_{t}=\ln S_{t}$ and choose for $\left(X_{t}\right)$ an Orstein-Uhlenbeck process driven under the pricing measure $Q$ by the

\footnotetext{
${ }^{3}$ See "Platts JKM ${ }^{\mathrm{TM}}$ (Japan Korea Marker) LNG price assessment". URL: https://bit.ly/2SMgcGN.
} 
FIGURE 2 JKM index spot price trajectory.

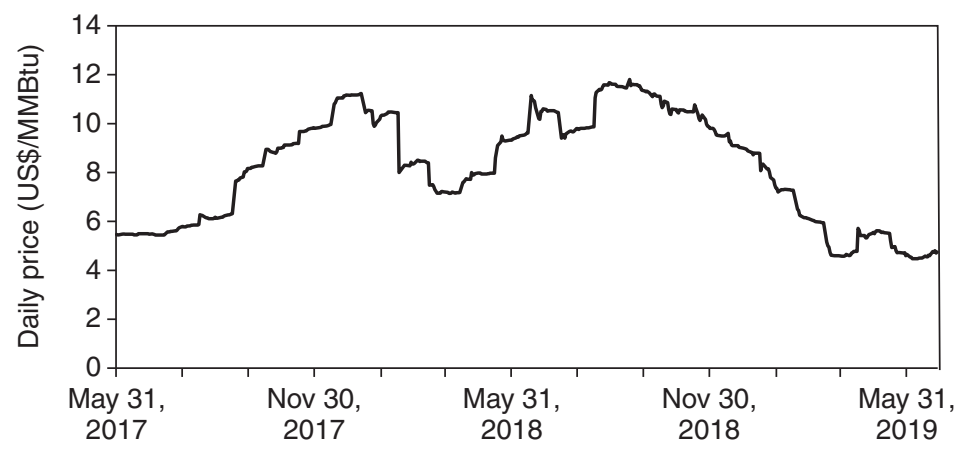

Daily prices presented in US $\$ / M M B t u$ for the JKM index for the period May 31, 2017-June 28, 2019. Source: Bloomberg.

following equations:

$$
\begin{aligned}
\mathrm{d} X_{t}^{\mathrm{G}}= & \kappa_{\mathrm{G}}\left(a_{\mathrm{G}}-X_{t}^{\mathrm{G}}\right) \mathrm{d} t+\sigma_{\mathrm{G}} \mathrm{d} W_{t}^{1}, \\
\mathrm{~d} X_{t}^{\mathrm{J}}= & \kappa_{\mathrm{J}}\left(a_{\mathrm{J}}-X_{t}^{\mathrm{J}}\right) \mathrm{d} t+\sigma_{\mathrm{J}} \mathrm{d} W_{t}^{2}, \\
& \mathrm{~d} W_{t}^{1} \mathrm{~d} W_{t}^{2}=\rho \mathrm{d} t,
\end{aligned}
$$

where $X_{t}^{\mathrm{G}}$ and $X_{t}^{\mathrm{J}}$ are the respective log prices for Germany and Japan, $a_{\mathrm{G}}$ and $a_{\mathrm{J}}$ are the respective levels of mean reversion for Germany and Japan, $\kappa_{\mathrm{G}}$ and $\kappa_{\mathrm{J}}$ are the respective speeds of mean reversion for Germany and Japan, and $W_{t}^{1}$ and $W_{t}^{2}$ are correlated $Q$ Brownian motions.

Since $X(T)=\ln S(T)$, the spot price at date $T$ is defined as

$$
\ln S(T)=\ln S(0) \mathrm{e}^{-k T}+a\left(1-\mathrm{e}^{-k T}\right)+\sigma \sqrt{\frac{1-\mathrm{e}^{-2 k T}}{2 k}} W(T) .
$$

Finally, the futures price $\ln F^{T}(0)$ is the $Q$ expectation of the spot price at date $T$ and satisfies

$$
\ln F^{T}(0)=\ln S(0) \mathrm{e}^{-k T}+a\left(1-\mathrm{e}^{-k T}\right)+\frac{\sigma^{2}}{4 k}\left(1-\mathrm{e}^{-2 k T}\right) .
$$

\subsection{Parameter estimation}

We estimate the three unknown parameters $a, k$ and $\sigma$ through the nonlinear least squares method using five different maturity futures contracts: the three-monthsahead, six-months-ahead, nine-months-ahead, twelve-months-ahead and eighteenmonths-ahead futures contracts. 
The nonlinear least squares estimator presented in (4.6) minimizes the sum of squared differences between the data set of historical values for each of the five different maturity futures contracts, and the futures price maturing at each of the five maturity contracts derived from the mean-reverting model (see (4.5)):

$$
\arg \min \left\{\sum_{i=1}^{5}\left[\ln F_{\text {market }}^{T_{i}}(0)-\ln F_{\text {Model }}^{T_{i}}(0)\right]^{2}\right\},
$$

where

$$
\begin{aligned}
& \ln F_{\text {model }}^{T_{1}}(0)=\ln S(0) \mathrm{e}^{-k 3 / 12}+a\left(1-\mathrm{e}^{-k 3 / 12}\right)+\frac{\sigma^{2}}{4 k}\left(1-\mathrm{e}^{-2 k 3 / 12}\right), \\
& \ln F_{\text {model }}^{T_{2}}(0)=\ln S(0) \mathrm{e}^{-k 6 / 12}+a\left(1-\mathrm{e}^{-k 6 / 12}\right)+\frac{\sigma^{2}}{4 k}\left(1-\mathrm{e}^{-2 k 6 / 12}\right), \\
& \ln F_{\text {model }}^{T_{3}}(0)=\ln S(0) \mathrm{e}^{-k 9 / 12}+a\left(1-\mathrm{e}^{-k 9 / 12}\right)+\frac{\sigma^{2}}{4 k}\left(1-\mathrm{e}^{-2 k 9 / 12}\right), \\
& \ln F_{\text {model }}^{T_{4}}(0)=\ln S(0) \mathrm{e}^{-k 12 / 12}+a\left(1-\mathrm{e}^{-k 12 / 12}\right)+\frac{\sigma^{2}}{4 k}\left(1-\mathrm{e}^{-2 k 12 / 12}\right), \\
& \ln F_{\text {model }}^{T_{5}}(0)=\ln S(0) \mathrm{e}^{-k 18 / 12}+a\left(1-\mathrm{e}^{-k 18 / 12}\right)+\frac{\sigma^{2}}{4 k}\left(1-\mathrm{e}^{-2 k 18 / 12}\right) ;
\end{aligned}
$$

$\ln S(0)$ is the data set of historical spot prices obtained at date $0 ; F_{\text {market }}^{T_{1}}(0)$, $F_{\text {market }}^{T_{2}}(0), F_{\text {market }}^{T_{3}}(0), F_{\text {market }}^{T_{4}}(0)$ and $F_{\text {market }}^{T_{5}}(0)$ are the data sets for the historical prices obtained at date 0 for the five different maturity futures contracts; and $T_{1}=3$ months, $T_{2}=6$ months, $T_{3}=9$ months, $T_{4}=12$ months and $T_{5}=18$ months.

The period of analysis used to estimate the parameters for the two indexes is not the same. This is due to the different operational start dates as well as the different availability of data across the various maturity futures contracts. For the GPL index, the period of analysis is October 31, 2013-June 28, 2019, and for the JKM index the period of analysis is May 31, 2017-June 28, 2019.

Table 1 shows the results of the parameter estimation. Both indexes exhibit a high volatility, which is not unexpected since natural gas prices, excluding electricity prices, are known to have the highest volatility among commodities (Geman 2005).

\subsection{LNG transportation costs}

The LNG transportation costs are an important component of the valuation of the rerouting option. Therefore, before turning to the pricing of the option, we first identify an estimation methodology for the additional transportation cost incurred by 
TABLE 1 Parameter estimation results.

\begin{tabular}{lccc}
\hline & JKM & GPL \\
\hline$\alpha$ & 1.6464 & 0.7671 \\
$\kappa$ & 1.3791 & 0.2995 \\
$\sigma$ & 1.2809 & 0.9434 \\
\hline
\end{tabular}

Nonlinear least squares estimation results for the three parameters using monthly historical data from five different maturity contracts.

delivering LNG to the alternative destination. We adopt the approach proposed by Rogers (2018), as this captures its key elements.

The transportation cost of LNG includes many components. The most important one is the daily charter rate of hiring an LNG vessel. In the early 2010s, shortterm LNG charter rates increased dramatically because of the growth in Asian LNG demand following the Fukushima disaster. Moreover, the LNG vessel market is divided into two types of vessels: steam turbine (ST) and dual fuel diesel electric (DFDE). ST vessels burn LNG boil-off and fuel oil to generate steam and in turn use turbines to generate propulsive drive. DFDE vessels use LNG boil-off in a diesel cycle engine that transmits energy to the ship's propellers. Since the early 2000s, DFDE vessels have been the preferred choice because they are $50 \%$ fuel efficient; ST vessels are only $28 \%$ efficient. Interestingly, DFDE carriers achieve an average speed of 19 knots without the need to burn fuel oil, whereas ST carriers achieve an average speed of 14 knots (Rogers 2018). Consequently, we decide to estimate the cost of delivering LNG using DFDE charter rates.

Figure 3 shows the weekly cargo charter rates for both DFDE and ST provided by Poten \& Partners for the period January 1, 2016-February 22, 2019. During 2016, and until the summer of 2017, the DFDE cargo charter rates were fluctuating around US\$50 000 per day. In November 2018, however, prices increased substantially to US\$170000 per day and subsequently decreased to US\$50000 per day in February 2019. Thus, in our study, we assume a US\$50 000 daily charter rate for a DFDE carrier.

Table 2 displays the breakdown of the various LNG transportation costs. These are (1) the charter cost, (2) the fuel cost, (3) the canal fee (depending on the route), (4) the ports cost for loading and unloading the LNG, (5) the broker fees and (6) the insurance fees. To obtain the transportation cost in US\$/MMBtu, we add the aforementioned six components and divide this by the amount of LNG delivered at the destination.

Table 3 presents the assumptions needed to obtain an estimation of transportation costs as well as a further deconstruction of the key components in the estimation methodology, in the spirit of Rogers (2018). 
FIGURE 3 Historical weekly cargo spot charter rates.

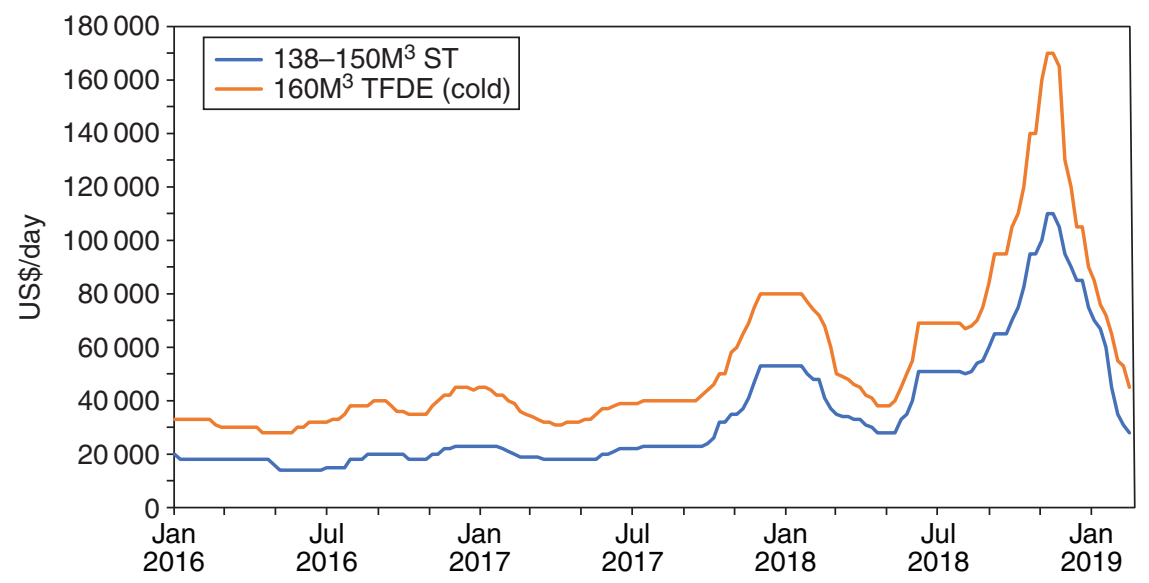

Weekly cargo spot charter rates for the period January 1, 2016-February 22, 2019 in US\$/day provided by Poten \& Partners. ST: steam turbine. DFDE: dual fuel diesel electric. Source: Poten \& Partners.

TABLE 2 Key components of the LNG transportation cost.

$\begin{array}{ll}1 & \text { Charter cost } \\ 2 & \text { Fuel cost } \\ 3 & \text { Canal fee } \\ 4 & \text { Ports cost } \\ 5 & \text { Broker/agent fees } \\ 6 & \text { Insurance fees } \\ 7 & \text { Amount of LNG delivered at destination }\end{array}$

Source: Rogers (2018).

In our study, the departure point for the LNG cargo is the Sabine Pass LNG terminal in Louisiana, US, operated by Cheniere Energy. The two arrival points for the LNG cargo are the Sodegaura terminal, the largest importing terminal in Japan operated by TEPCO and Tokyo Gas, and the Brunsbuttel site, where the first German LNG terminal is under construction.

Table 4 presents the breakdown and the final transportation cost in US\$/MMBtu for a return journey for the two points of arrival. The US-Japan route has an additional fee for the Panama Canal, whereas the other route (US-Germany) has no such extra charge. We also observe that the transportation cost of LNG when the recipient is Japan instead of Germany is much higher. The US-Japan route costs US\$1.20/MMBtu, whereas the US-Germany route costs US\$0.58/MMBtu. 
TABLE 3 Breakdown of key components.

\begin{tabular}{|c|c|}
\hline Charter cost & $\begin{array}{l}\text { Number of days for the entire journey multiplied by the } \\
\text { daily charter rate }\end{array}$ \\
\hline Fuel cost & $\begin{array}{l}\text { Number of days for the entire journey multiplied by the } \\
\text { opportunity cost of LNG boil-off }\end{array}$ \\
\hline $\begin{array}{l}\text { Opportunity cost of } \\
\text { LNG boil-off }\end{array}$ & $\begin{array}{l}\text { Daily LNG boil-off, which is } 0.101318 \% \text { of cargo size } \\
\text { multiplied by the spot price at destination (US } \$ \text { MMBtu) }\end{array}$ \\
\hline Suez Canal cost & US\$400000 \\
\hline Panama Canal cost & $\begin{array}{l}\text { US } \$ 0.2 / M M B t u \text { multiplied by the amount of LNG } \\
\text { delivered at destination }\end{array}$ \\
\hline Ports cost & $\begin{array}{l}\text { US } \$ 100000 \text { per day; time spent at ports is three days } \\
\text { for the entire journey: outbound port, destination port } \\
\text { and return port }\end{array}$ \\
\hline Broker/agent fees & $2 \%$ of the total charter cost \\
\hline Insurance fees & US $\$ 2600$ per day \\
\hline $\begin{array}{l}\text { Amount of LNG } \\
\text { delivered at destination }\end{array}$ & $\begin{array}{l}\text { Initial loading, which is } 98 \% \text { minus the reserved heel for } \\
\text { the return journey, which is } 4 \% \text { of the initial loading } \\
\text { minus the boil-off for the entire journey }\end{array}$ \\
\hline Vessel type & DFDE \\
\hline Vessel size & 160000 cubic meters of LNG \\
\hline $\begin{array}{l}\text { LNG cubic meters to } \\
\text { MMBtu }\end{array}$ & 23.12 \\
\hline $\begin{array}{l}\text { Route and number of } \\
\text { days of journey }\end{array}$ & https://sea-distances.org/ \\
\hline Average carrier speed & 19 knots \\
\hline
\end{tabular}

Breakdown of key components and assumptions used in the estimation of the LNG transportation cost for a return journey. Source: Rogers (2018).

The rerouting option is a spread option involving the additional transportation cost incurred if the cargo is redirected to Japan. Specifically, this one is the transportation cost for a journey from Germany to Japan, plus the difference in transportation costs between Japan and Germany, back to the supplier's terminal. The additional transportation cost (ATC) is defined in (4.7), and the results are presented in Table 5. We find that the additional transportation cost is US\$0.98/MMBtu:

$$
\mathrm{ATC}=\mathrm{TC}^{\text {Germany-Japan }}+\mathrm{TC}^{\mathrm{Japan}-\mathrm{US}}-\mathrm{TC}^{\text {Germany-US }},
$$

where $\mathrm{TC}^{\text {Germany-Japan }}$ is the transportation cost from Germany to Japan (single journey), TC $\mathrm{Japan}^{\mathrm{J}-\mathrm{US}}$ is the transportation cost from Japan back to the supplier's terminal (single journey), and TC ${ }^{\text {Germany-US }}$ is the transportation cost from Germany back to the supplier's terminal (single journey). 
TABLE 4 Results: LNG transportation cost.

\begin{tabular}{|c|c|c|}
\hline & US-Japan & US-Germany \\
\hline Charter cost & US\$2 170175 & US\$1 279386 \\
\hline Fuel cost & US\$704 909 & US\$283739 \\
\hline Canal fee & US\$666 361 & US\$0 \\
\hline Ports cost & US $\$ 300000$ & US $\$ 300000$ \\
\hline Broker/agent fees & US\$43404 & US\$25 588 \\
\hline Insurance fees & US\$112849 & US\$66 528 \\
\hline $\begin{array}{l}\text { LNG volume delivered } \\
\text { at destination }\end{array}$ & US\$3 331805 & US\$3 397243 \\
\hline Total cost US\$/MMBtu & US\$1.20/MMBtu & US\$0.58/MMBtu \\
\hline
\end{tabular}

LNG transportation cost for a return journey for the two routes.

TABLE 5 Results: additional LNG transportation cost (ATC).

\begin{tabular}{ll}
\multicolumn{1}{c}{ Route } & US\$/MMBtu \\
\hline TCGermany-Japan & 0.67 \\
TC Japan-US & 0.60 \\
TCGermany-US & 0.29 \\
ATC & 0.98 \\
\hline
\end{tabular}

Results for the additional LNG transportation cost incurred from cargo rerouting.

\section{VALUATION OF THE REROUTING OPTION}

We identify the rerouting option as a spread option, defined in (3.1), for which only the Kirk approximation gives some kind of explicit approximation in the case of a geometric Brownian motion assumption for the two variables at stake. In our case, we recognize mean-reverting processes in the LNG spot and forward prices; hence, from all perspectives, a Monte Carlo approach is the right way to proceed to compute the option price as the $Q$ expectation at date 0 of the payoff at date $T$. Note that the discount should be factored in from date $T$ to date 0 , since the option is only cashed at date $T$, which is the maturity of the forward contract sold at date $T_{1}$ when reaching Germany:

$$
C(0)=\mathrm{e}^{-r T} E_{Q}\left[\max \left(0, f_{\mathrm{J}}^{T}\left(T_{1}\right)-S_{\mathrm{G}}\left(T_{1}\right)-\mathrm{ATC}\right) / F_{0}\right]
$$

It is important to observe that this is the added value granted at date 0 by the destination optionality; its payoff will take place at date $T_{1}$. The spot price of LNG 
in Germany at date $T_{1}$ is

$$
\ln S_{\mathrm{G}}\left(T_{1}\right)=\ln S_{\mathrm{G}}(0) \mathrm{e}^{-k_{\mathrm{G}} T_{1}}+a_{\mathrm{G}}\left(1-\mathrm{e}^{-k_{\mathrm{G}} T_{1}}\right)+\sigma_{\mathrm{G}} \sqrt{\frac{1-\mathrm{e}^{-2 k_{\mathrm{G}} T_{1}}}{2 k_{\mathrm{G}}}} W_{1}\left(T_{1}\right)
$$

The expectation at date 0 of the forward price in Japan at date $T_{1}$ for LNG delivery at date $T$ is derived from the law of iterated expectations:

$$
E\left[f_{\mathrm{J}}^{T}\left(T_{1}\right) / F_{0}\right]=E\left[E\left[S_{\mathrm{J}}(T) / F_{T_{1}}\right] / F_{0}\right]=E\left[S_{\mathrm{J}}(T) / F_{0}\right],
$$

where

$$
\ln S_{\mathrm{J}}(T)=\ln S_{\mathrm{J}}(0) \mathrm{e}^{-k_{\mathrm{J}} T}+a_{\mathrm{J}}\left(1-\mathrm{e}^{-k_{\mathrm{J}} T}\right)+\sigma_{\mathrm{J}} \sqrt{\frac{1-\mathrm{e}^{-2 k_{\mathrm{J}} T}}{2 k_{\mathrm{J}}}} W_{2}(T)
$$

will be the Monte Carlo-simulated quantity.

Next, we exponentiate (5.3) and (5.4):

$$
\begin{aligned}
& S_{\mathrm{G}}\left(T_{1}\right)=\exp \left\{\ln S_{\mathrm{G}}(0) \mathrm{e}^{-k_{\mathrm{G}} T_{1}}+a_{\mathrm{G}}\left(1-\mathrm{e}^{-k_{\mathrm{G}} T_{1}}\right)+\sigma_{\mathrm{G}} \sqrt{\frac{1-\mathrm{e}^{-2 k_{\mathrm{G}} T_{1}}}{2 k_{\mathrm{G}}}} W_{1}\left(T_{1}\right)\right\}, \\
& S_{\mathrm{J}}(T)=\exp \left\{\ln S_{\mathrm{J}}(0) \mathrm{e}^{-k_{\mathrm{J}} T}+a_{\mathrm{J}}\left(1-\mathrm{e}^{-k_{\mathrm{J}} T}\right)+\sigma_{\mathrm{J}} \sqrt{\frac{1-\mathrm{e}^{-2 k_{\mathrm{J}} T}}{2 k_{\mathrm{J}}}} W_{2}(T)\right\} \cdot
\end{aligned}
$$

In order to perform a Monte Carlo valuation of the option, we introduce a new Brownian motion $W_{3}$. This is defined as

$$
W_{3}=\rho W_{1}+\sqrt{1-\rho^{2}} W_{2},
$$

according to the Cholesky decomposition. We compute Pearson's correlation between the two spot prices for the first three months and identify that the correlation coefficient is approximately 0.5. Lastly, we simulate price values driven by (5.5) and (5.6) and approximate the rerouting option's price at date 0 :

$$
C(0)=\mathrm{e}^{-r T} \sum_{1}^{n} \frac{\max \left(0, S_{\mathrm{J}}(T)-S_{\mathrm{G}}\left(T_{1}\right)-\mathrm{ATC}\right)}{n} .
$$

Here, $r$ is the interest rate, assumed to be $3 \%$, and $n$ is the number of simulations, set to 10000 .

\subsection{Results}

The option price we obtain with the values of the parameters discussed in Section 4.2 is US\$0.856/MMBtu (see Table 6). The buyer of an LNG cargo delivered from the 
TABLE 6 Rerouting option price and P\&L strategies 1 and 2.

US\$/MMBtu

Rerouting option price

P\&L strategy 1: carry trade delivery Japan

P\&L strategy 2: carry trade delivery Germany + rerouting option

The rerouting option's price is presented alongside the P\&L of the two strategies.

United States to either Germany or Japan has two strategies available to them. The first strategy is to buy the LNG from the US supplier at date 0 (US\$2.31/MMBtu) and sell a forward contract in Japan (US\$4.75/MMBtu) leading to a profit and loss (P\&L) at date $T$ of US\$1.24/MMBtu (accounting for the LNG transportation cost). The second strategy is to enter a forward contract delivery with Germany with a rerouting option attached. The rerouting option represents the additional profit the buyer will acquire on average across the voyages. In this case, the P\&L of the strategy will amount to US\$1.39/MMBtu - for the forward contract destination of Germany (US\$0.53/MMBtu) plus the rerouting option - which is higher than the P\&L of the carry trade delivery to Japan: an additional gain of $12 \%$.

The rerouting option being added to the forward contract destination of Germany as opposed to the pure forward destination of Japan will be particularly valuable when the LNG tanker reaches Germany during cold winters or during periods when the natural gas pipeline from Russia gets stopped by operational or political issues, creating spikes in German spot prices: see Figure 4 for the historical daily gas prices in Germany from January 2016 until June 2019 and the spike observed in the second half of 2018, leading to a very high P\&L obtained through the option.

Lastly, we test the option's price sensitivity in terms of volatility. We compute the option price when volatility $\sigma_{\mathrm{J}}$ is increased by $20 \%, 30 \%$ and $50 \%$, successively, and then compare the new option prices with the original option price. Our results, presented in Table 7, show that a higher volatility affects the option's payoff positively: increases of $16 \%, 25 \%$ and $44 \%$ result from volatility increases of $20 \%, 30 \%$ and $50 \%$, respectively.

\section{CONCLUSION}

New flexible, short-term LNG contracts and the subsequent emergence of rerouting optionality are transforming the LNG market, while LNG has become a commodity in its own right. In this paper, we described the rerouting option granted to the buyer at departure of the tanker in a specific choice of countries and proposed a valuation methodology that extends the founding option pricing models due to both the 
FIGURE 4 GPL index spot price trajectory: daily prices.

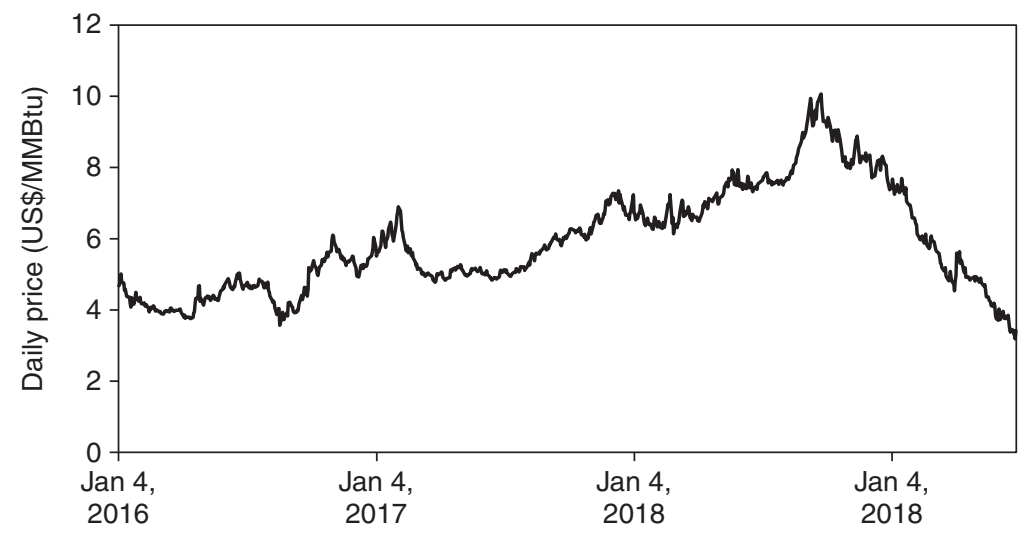

Daily prices presented in US\$/MMBtu for the German GPL for the period January 4, 2016-June 28, 2019. Source: Bloomberg.

TABLE 7 Option price's sensitivity to volatility.

\begin{tabular}{lcccc}
\hline \multicolumn{1}{c}{ Supplier } & $\boldsymbol{C}(\mathbf{0})$ original & $\boldsymbol{C}(\mathbf{0})$ when $\sigma_{\mathrm{J}}+\mathbf{2 0 \%}$ & $\boldsymbol{C}(\mathbf{0})$ when $\sigma_{\mathrm{J}}+\mathbf{3 0 \%}$ & $\boldsymbol{C}(\mathbf{0})$ when $\sigma_{\mathrm{J}}+\mathbf{5 0 \%}$ \\
\hline US & US $\$ 0.856 / \mathrm{MMBtu}$ & US $\$ 0.996 / \mathrm{MMBtu}$ & US $\$ 1.07 / \mathrm{MMBtu}$ & US $\$ 1.23 / \mathrm{MMBtu}$ \\
$\%$ change & - & $16 \%$ & $25 \%$ & $44 \%$ \\
compared to & & & & \\
$C(0)$ original & & & & \\
\hline
\end{tabular}

Results of the rerouting option's price in the case where the volatility $\left(\sigma_{J}\right)$ is increased by $20 \%, 30 \%$ and $50 \%$.

payoff and the mean-reversion chosen for the spot prices. The profitability behind this optionality being embedded in a purchase contract - as well as its sensitivity to transportation costs, price volatility and spikes - is also exhibited.

\section{DECLARATION OF INTEREST}

The authors report no conflicts of interest. The authors alone are responsible for the content and writing of the paper.

\section{REFERENCES}

Carriere, C. (2018). The effects of Japan's push for greater LNG market flexibility on LNG pricing and destination restrictions. Journal of World Energy Law and Business 11, 136-144 (https://doi.org/10.1093/jwelb/jwy002).

Corbeau, A., and Ledesma, D. (2016). LNG Markets in Transition: The Great Reconfiguration. Oxford Institute for Energy Studies. 
Dixit, A. K., and Pindyck, R. S. (1994). Investment Under Uncertainty. Princeton University Press (https://doi.org/10.1515/9781400830176).

Flower, A. (2016). LNG supply outlook 2016 to 2030. Report, Centre for Energy Economics.

Geman, H. (2005). Commodities and Commodity Derivatives, Modelling and Pricing for Agriculturals Metals and Energy. Wiley.

Hartley, P. (2015). The future of long-term LNG contracts. Energy Journal 36(3), 209-233 (https://doi.org/10.5547/01956574.36.3.phar).

International Gas Union (2018). 2019 world LNG report. Report, June 23, IGU.

Jensen, J. T. (2004). The development of a global LNG market: is it likely? If so when? Research Paper NG 5, Oxford Institute for Energy Studies.

Ledesma, D., and Fulwood, M. (2019). New players, new models: a research think piece. Executive Summary, March, Oxford Institute for Energy Studies.

Mills, M. (2018). American LNG will meet Europe's urgent need for gas. Financial Times, October 23. URL: https://on.ft.com/3iSJ7UB.

Rodriguez, R. Y. (2008). Real option valuation of free destination in long-term liquefied natural gas supplies. Energy Economics 30, 1909-1932 (https://doi.org/10.1016/j.eneco .2007.03.006).

Rogers, H. (2018). The LNG shipping forecast: costs rebounding, outlook uncertain. Energy Insight 27, March, Oxford Institute for Energy Studies.

Shi, X., Malamakkavu, H., and Variam, P. (2016). Gas and LNG trading hubs, hub indexation and destination flexibility in East Asia. Energy Policy 96, 587-596 (https://doi.org/ 10.1016/j.enpol.2016.06.032).

US Energy Information Administration (2019). US net natural gas exports in first-half 2019 doubles year-ago levels for second year. Article, October 29, EIA. URL: https://www.eia .gov/todayinenergy/detail.php?id=41713. 
